\title{
Gamma Dose Rate Measurements in Kuwait Using a Car-Borne GPS Integrated Dosimetric System
}

\author{
Darwish Al-Azmi \\ Department of Applied Sciences, College of Technological Studies, Public Authority for Applied Education and \\ Training, Shuwaikh, Kuwait \\ Email: ds.alazmi@paaet.edu.kw, dalazmi@yahoo.co.uk
}

Received 19 May 2014; revised 25 June 2014; accepted 5 July 2014

Copyright (C) 2014 by author and Scientific Research Publishing Inc. This work is licensed under the Creative Commons Attribution International License (CC BY). http://creativecommons.org/licenses/by/4.0/ c) (i) Open Access

\begin{abstract}
A mobile system comprising of a Geiger-Muller (GM) dosimeter connected with a smart phone was used for ambient gamma dose rate survey within the districts and on the roads within the state of Kuwait. While the dosimeter provides data on gamma dose rates, the smart phone provides the GPS navigation information and saves the data for subsequent analysis and mapping. The survey covered a total distance of about $2300 \mathrm{~km}$ within the country and 3117 data points were recorded to show the dose rate distribution on the map of Kuwait. The results show that the ambient dose rates in Kuwait range from 40 to $180 \mathrm{nSv} \cdot \mathrm{h}^{-1}$ with a mean value of $103 \mathrm{nSv} \cdot \mathrm{h}^{-1}$. The dosimetric system described has good potential as a tool for determining baseline background radiation dose rates in an area.
\end{abstract}

\section{Keywords}

\section{Car-Borne Dosimeter, Mobile Measurements, Dose Rate, GM Dosimeter, Kuwait}

\section{Introduction}

Temporal and spatial variations of the background radiation levels may be caused by various human activities, such as mining, nuclear weapon tests, accidental or normal releases from nuclear power reactors, etc. It is important to develop capacity to delineate the influence of such activities on the natural background radiation levels, and it is equally important to be able to establish the baseline levels. Environmental surveys meant for establishing the gamma dose rates baseline within a country may be carried out using a number of different techniques and methods. One of the approaches is to mount the dosimetric system on a vehicle and drive along the main 
motorways and interior roads and streets in the districts/towns and villages of specific regions to search for dose rate anomalies. Such car-borne measuring systems provide much faster and greater coverage than what could be achieved by moving around on foot with a portable system. A number of mobile systems dedicated for such applications have been reported [1]. Car-borne measurements were carried out successfully in Taiwan and an enhanced radioactivity levels were detected in one of the streets in that survey. The findings necessitated a detailed study on the construction materials used for the street surface and this led to the removal of the top surface layer of the contaminated section of the street [2]. In another study in Taiwan, a train was equipped with a radiation measurement system consisting of four types of radiation detectors to measure different components of natural background radiation; cosmic-rays, neutrons, gamma dose rates and spectrometric gamma-ray measurements [3]. In general, the common and adequate arrangement for mobile measurements while driving a car may comprise gamma spectrometer and/or a handheld GM dosimeter [4], or simply a dosimeter connected with a GPS navigation system [5].

Moreover, some of the radiation dosimeters have an automatic data logging feature which may be utilized to register dose rate data alongside with the global positioning navigation system (GPS) information, allowing for plotting the readings obtained on the map of the study area in a smooth and encouraging/interesting way while moving around. Thus, wide areas and long distances can be covered easily in short-term surveys.

\section{Materials and Methods}

\subsection{The Study Area}

Kuwait is located in the north-east corner of the Arabian Peninsula; on the northern coastal area of the Arabian Gulf. It is between latitudes 28 and 31 north and longitudes 46 and 49 east. The country is flat with altitudes reaching about $300 \mathrm{~m}$ in the west. Kuwait is a desert type country with relatively uniform sandy areas and low concentrations of ${ }^{40} \mathrm{~K},{ }^{226} \mathrm{Ra},{ }^{238} \mathrm{U}$ and ${ }^{232} \mathrm{Th}$ with average values of 332, $11.8,13.3$ and $10 \mathrm{~Bq} \cdot \mathrm{kg}^{-1}$, respectively [6].

Kuwait is a modern country with most houses build in recent years. The house construction is typically of concrete and cement bricks. All roads and streets in Kuwait are well paved and covered with asphalt, and all districts have new streets. The county has a modern motorway network.

Within the last two decades, the subject of background radiation and radionuclide identification became a concern in Kuwait due to the Gulf War Conflict and its related issue of the "Depleted Uranium". Scientific literature shows that the radiation background in Kuwait is within the normal levels and no anomalous were found [7].

\subsection{The Gamma Dosimeter}

The gamma radiation dosimeter used in the present work is a Geiger-Muller (GM) based system "BlueGeiger PG-15” from Kindenoo, France, Figure 1. This device has an inbuilt Bluetooth communication system and this enables uploading and sharing applications with another device through the SPP protocol data transfer. The dose rate values are recorded for every $6 \mathrm{~s}$ by the dosimeter and then transmitted to the personal phone where the average is obtained every 2 minutes and then recorded together with the corresponding GPS location information to allow the visualization of the readings on a map. This represents a simplified car-borne (or mobile) system for dose rate measurements while moving. A dedicated application has been created for Android ${ }^{\mathrm{TM}}$ cell phones or tablets.

The measurement range is 0.05 to $300 \mu \mathrm{Sv} \cdot \mathrm{h}^{-1}$ with accuracy of $\pm 10 \%$ and the calibration was approved by the IRSN (France). The dosimeter is light in weight (124 g without batteries) and works with either one or two AA batteries (alkaline or rechargeable) up to 60 hours when two batteries are used.

Furthermore, the data may be shared on the web by the Android ${ }^{\mathrm{TM}}$ application, in a specific server. It is possible to export the data to other software packages like Excel ${ }^{\circledR}$ and geographical software package (like GoogleEarth $^{\circledR}$.

\subsection{Dose Rate Measurements and Mapping of the Area}

Initial test measurements were performed for the BlueGeiger dosimeter with another dosimeter "AlphaGuard GM dosimeter" for a comparison. The AlphaGuard radon monitor, which is equipped with a gamma-ray GM 


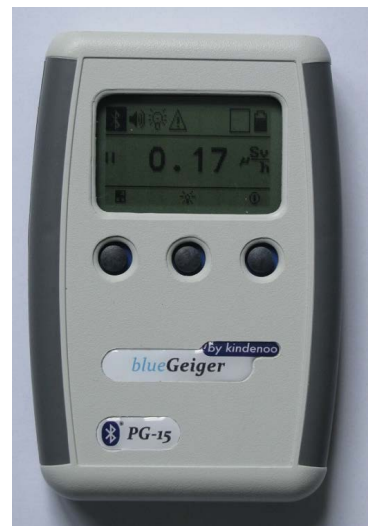

Figure 1. The BlueGeiger PG-15 dosimeter.

dosimeter is available in our laboratory and it is factory-calibrated. The comparison measurements were carried out for both instruments kept next to each other inside a $10-\mathrm{cm}$ lead shield and in an indoor location for a period of 3 hours each.

Dose rate survey was carried out using the BlueGeiger PG-15 dosimetric system through many car trips within Kuwait from time to time to acquire data during the period from June 2012 to August 2013. Repeated measurements were carried out in many of the sectors/regions to ensure the reproducibility of the measured data and increase the data collection.

The survey in Kuwait covered most of the areas with the following categories:

All districts in Kuwait (driving through the paved streets between the house blocks), roads and motorways, some selected areas and regions such as the scrap yard and a farming area.

\section{Results}

\subsection{Test Measurement}

Table 1 presents a comparison of the data obtained from the BlueGeiger PG-15 and the AlphaGuard dosimeters during the test measurements. The BlueGeiger PG-15 provided data which are higher, $30-40 \mathrm{nSv} \cdot \mathrm{h}^{-1} \mathrm{when}$ compared to those of AlphaGuard. The readings recorded with the BlueGeiger show a wider range of data due to the shorter sampling time interval of 2 minutes when compared to the 10 minute sampling interval of the other dosimeter [8] [9] and probably due to a difference in sensitivity.

\subsection{Survey Results}

In Figure 2, the map of Kuwait is presented showing all the locations where the measurements were recorded. Each dot on the map represents a measuring point of the dose rate. In total, dose rates were measured at 3077 points. In addition to this, there are 40 data points which could not be inserted on the map due to the missing GPS position information (poor satellite coverage) and hence the difficulty in identifying their precise location on the map. Such 40 data points are within the dose range of whole distribution. The gamma dose rates varied in the range of $40-180 \mathrm{nSv} \cdot \mathrm{h}^{-1}$ with an overall average mean value of $103 \mathrm{nSv} \cdot \mathrm{h}^{-1}$. The frequency distribution for the whole recorded data of the dose rates is presented in Figure 3.

The vehicle was driven at slow to moderate speeds $\left(20-40 \mathrm{~km} \cdot \mathrm{h}^{-1}\right)$ on the streets between the districts and at speeds of $100-120 \mathrm{~km} \cdot \mathrm{h}^{-1}$ on the main roads and motorways. The average speed of the car was about $21 \mathrm{~km} \cdot \mathrm{h}^{-1}$ while recording the data inside the districts and this implies that the distance between the measurement points was about $0.75 \mathrm{~km}$, whereas it was about $3.1 \mathrm{~km}$ for the motorways. In Table 2, the sampling distances and traveled time are presented for two measurements.

\subsection{Districts, Regions and Roads within Kuwait Covered in the Survey}

Presented in Table 3 are the dose rate results for some of selected inhabitant areas (districts), specific regions and a motorway in Kuwait. Following is a brief description and comments of such regions. 
Table 1. Comparison of the results of gamma dose rates measured using the BlueGeiger PG-15 and AlphaGuard dosimeters.

\begin{tabular}{|c|c|c|}
\hline & \multicolumn{2}{|c|}{ Mean value of dose rate $n S v \cdot h^{-1}$ (range of data $n S v \cdot h^{-1}$ ) } \\
\hline & BlueGeiger PG-15 (2 min sampling) & AlphaGuard GM dosimeter (10 min sampling) \\
\hline Inside 10-cm lead shield & $61.8(20-100)$ & $30.6(14-52)$ \\
\hline Indoor location & $134.4(70-190)$ & $94.6(76-108)$ \\
\hline
\end{tabular}

Table 2. Sampling distances and time of measurements within a district and on a road.

\begin{tabular}{lcc}
\hline Location & Faiha district & $\begin{array}{c}\text { Motorway from Kuwait City to } \\
\text { southern border }\end{array}$ \\
\hline Traveled distance $(\mathbf{k m})$ & 19.6 & 105 \\
Time (minutes) & 57 & 75 \\
Number of data points recorded & 26 & 34 \\
Effective speed of vehicle $\left(\mathbf{k m} \cdot \mathbf{h}^{-\mathbf{1}}\right)$ & 20.6 & 84 \\
Effective sampling distance between data points $\mathbf{( k m )}$ & 0.75 & 3.1 \\
\hline
\end{tabular}

Table 3. Comparison of the gamma dose rates of some selected districts and regions from the different Governorates in Kuwait.

\begin{tabular}{|c|c|c|c|c|}
\hline \multirow{2}{*}{\multicolumn{2}{|c|}{ Districts Regions and Roads }} & \multirow{2}{*}{ \# of data points } & \multicolumn{2}{|c|}{ Dose rate $\left(\mathrm{nSv} \cdot \mathrm{h}^{-1}\right)$} \\
\hline & & & Range & Average value \\
\hline & Kuwait City & 67 & $60-150$ & 109 \\
\hline & Al-Jahra City and its area & 191 & $60-150$ & 100 \\
\hline \multirow{4}{*}{$\begin{array}{l}\text { Regions, Roads and } \\
\text { Motorways }\end{array}$} & Al-Ahmadi City & 65 & $70-170$ & 109 \\
\hline & Al-Wafra Farming Area & 61 & $40-170$ & 111 \\
\hline & Scrap Area & 58 & $50-140$ & 103 \\
\hline & Motorway & 34 & $70-140$ & 107 \\
\hline \multicolumn{2}{|c|}{ All areas of Kuwait } & 3077 & $40-180$ & 103 \\
\hline \multicolumn{2}{|c|}{ All areas of Kuwait (with the GPS missing data included) } & 3117 & $40-180$ & 103 \\
\hline
\end{tabular}

\subsubsection{Kuwait City}

Kuwait City, the capital of the State of Kuwait, represents an old as well as modern city with a trend of the appearance of high rise buildings.

\subsubsection{Al-Jahra City and Its Area}

An old city in western Kuwait, Al-Jahra: The survey covered the old part of the city and its surrounding new districts. Although it is one of the oldest cities in Kuwait, the house construction is new. In fact, it represents (like the great majority of other districts in the country) a typical modern district area with new houses and paved streets.

\subsubsection{Al-Ahmadi City}

Al-Ahmadi, in southern Kuwait, is considered as one of the old cities build in the 1940's as a district to house the head quarter for Kuwait Oil Company and the workers.

\subsubsection{Al-Wafra Farming Area}

Al-Wafra is the southernmost city in Kuwait and is well known for its fertile soil and farms. A car trip was carried out on the asphalt roads between the farms as well as a couple of walks on the ground of two farms. The dose rate recorded for this region varied in the range of $40-170 \mathrm{nSv} \cdot \mathrm{h}^{-1}$ with a mean value was of $111 \mathrm{nSv} \cdot \mathrm{h}^{-1}$. In the measurements performed in two farms, the dosimeter was kept on the same height as in the car while moving on the grass. 


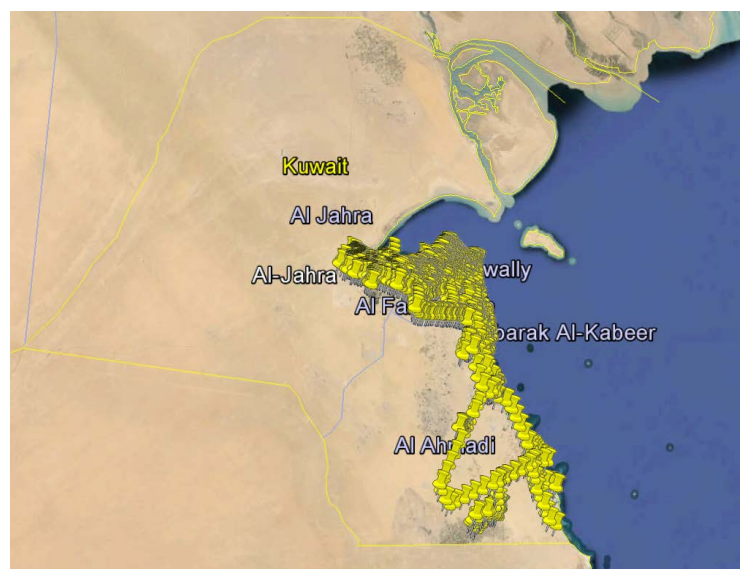

(a)

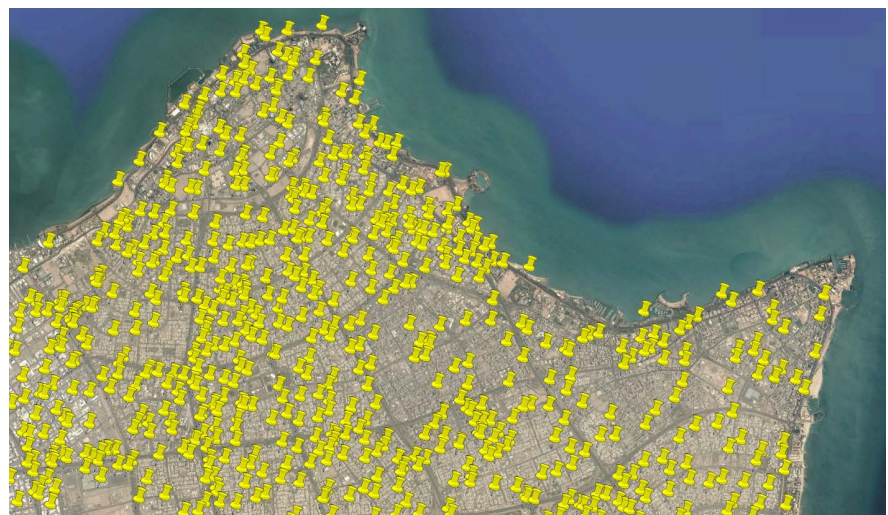

(c)

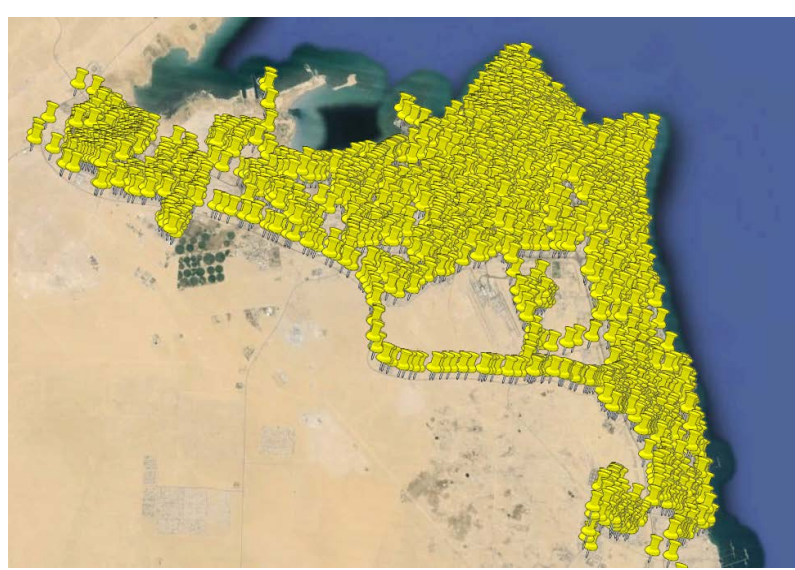

(b)

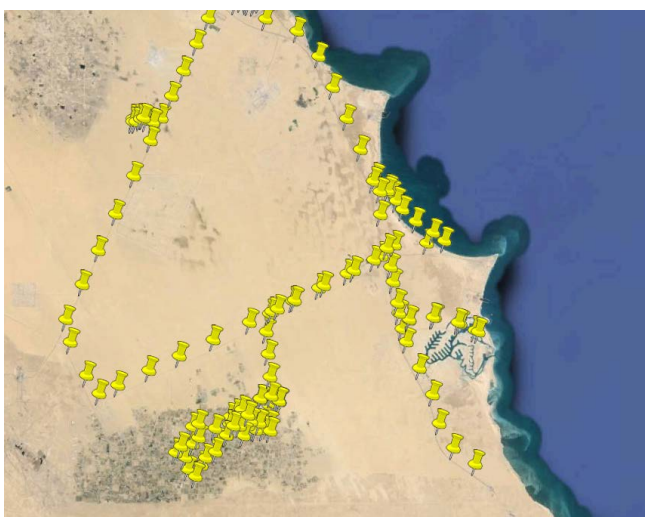

(d)

Figure 2. The map of Kuwait showing all the locations covered in the survey. (a) The entire region covered under the study, where most districts are involved. (b) and (c) Expanded views of the dose map. (d) Some of the main roads and Al-Wafra farming area in southern Kuwait.

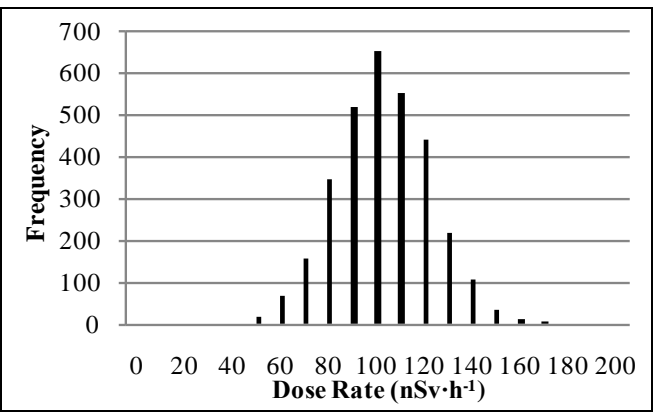

Figure 3. The frequency distribution of the ambient dose rate values recorded for all regions of Kuwait $(\mathrm{N}=3117$ data points), from Figure 2 with the added 40 data points.

\subsubsection{The Scrap Yard and Amgarah Industrial Area}

The vehicle was driven through the blocks of the scrap yard. The results show that the values obtained for the dose rate data for this area are comparable with the rest of the regions within Kuwait. This indicates that the situation is very clear within the scrap yard in Kuwait.

\subsubsection{One of the Motorways in Kuwait}

The readings are presented in the graph of Figure 4 show the variations of the dose rate during the trip on the 


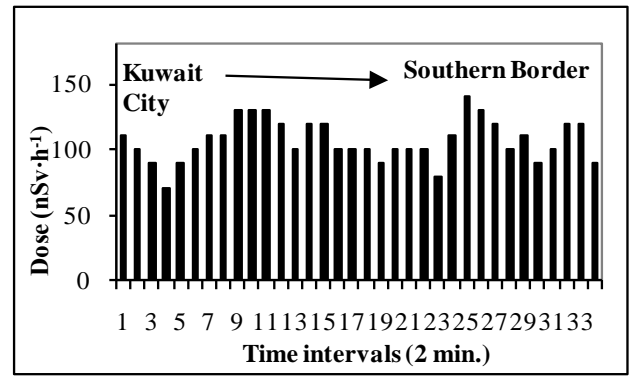

Figure 4. Variation of the dose rate during the trip on the motorway from Kuwait City to the southern border. Traveled distance was $105 \mathrm{~km}$ and sampling point for every $3.1 \mathrm{~km}$ on an average.

motorway from Kuwait City to the southern border with a traveled distance of $105 \mathrm{~km}$ and a sampling point for every $3.1 \mathrm{~km}$ on average. The mean dose rate value was $107 \mathrm{nSv} \cdot \mathrm{h}^{-1}$, with the range of $70-140 \mathrm{nSv} \cdot \mathrm{h}^{-1}$.

\section{Discussion}

The present work highlights the usefulness of using a car-borne measuring system for easy and fast dose rate measurements in a large-area survey. Assuming an effective sampling distance of $0.75 \mathrm{~km}$ as measured within the districts and longer sampling distances on the roads and motorways, an overall distance of not less than 2300 $\mathrm{km}$ has been covered with 3117 data points within this survey in Kuwait.

The recorded measurements indicate that the levels of the dose rates in Kuwait are within the normal range as compared with world average [10]. The overall results for the dose rates have been found to be in the range of $40-180 \mathrm{nSv} \cdot \mathrm{h}^{-1}$ with a mean average value of $103 \mathrm{nSv} \cdot \mathrm{h}^{-1}$ for the measurements performed mainly on the asphalt while driving the vehicle on the streets and roads showing that no increased radioactivity is present in the materials used for the road construction or the surrounding areas. Whereas, for few measurements that were carried out in off-road points in southern Kuwait on a sandy area, the mean dose rate value was $91 \mathrm{nSv} \cdot \mathrm{h}^{-1}$ (range of $70-120 \mathrm{nSv} \cdot \mathrm{h}^{-1}, \mathrm{~N}=9$ ). In fact, there are two sampling points showing the dose rate value of $40 \mathrm{nSv} \cdot \mathrm{h}^{-1}$ within the streets of a district and on a road of the Al-Wafra farm area. The highest dose rate of $180 \mathrm{nSv} \cdot \mathrm{h}^{-1}$ was measured on a road in the Doha area (about $1.5 \mathrm{~km}$ from the sea coast).

The use of a low-sensitive detection device such as the Geiger-Muller dosimeter with a short sampling time interval results in a wide range of recorded data [8] [9]. Thus, the mean values of the measurements should be considered for each specific region [5]. Nevertheless, the results presented in Figure 4 for the measurements taken over a long drive on the motorway show some kind of consistency where the dose rate values do not exhibit large or sudden variations.

Although the readings from the present GM dosimeter used throughout this survey are assumed to be overestimated by $30-40 \mathrm{nSv} \cdot \mathrm{h}^{-1}$ when compared with another GM dosimeter as observed during the test measurements, this should not have a negative effect on the overall results, considering the fact that the obtained results for Kuwait are within the radiation levels in the range of reported normal background regions of the world. One should consider the fact that the readings obtained in this study with a GM dosimeter include the dose rate component due to the cosmic radiation [8] of about $32 \mathrm{nSv} \cdot \mathrm{h}^{-1}$ at sea level for Kuwait.

\section{Conclusions}

The use of a car-borne/mobile measurement system is an effective practical way to quickly obtain database on the radiation background levels in a region.

The system may be used as a complimentary measuring device to provide the values for the dose rates during the routine trips. The easy way of data acquisition makes it possible to acquire a large number of measurements for the professionals who are engaged in the field of environmental radiation measurements, and then select part(s) of the data from the map utilizing their GPS locations to isolate certain geographical regions for an individual presentation or further analysis.

This study has provided a clear idea about the dose rates in Kuwait on the paved streets and roads within the districts. The gamma dose rate, in the region covered under this study, varied in the range of $40-180 \mathrm{nSv} \cdot \mathrm{h}^{-1}$ 
with an overall mean value of $103 \mathrm{nSv} \cdot \mathrm{h}^{-1}$. The dosimetric system described has good potential as a tool for determining baseline background radiation dose rates in an area. These results from the present work confirm that there are no anomalies in the dose rates in Kuwait as it has already found out in a reported study for the calculated dose rates from collected soil samples [11].

\section{References}

[1] Smethurst, M.A., Mogaard, J.O. and Koziel, J. (2005) NGU Report 2005.026: A Mobile Gamma Ray Spectrometer System for Nuclear Hazard Mapping: GAMMALOG v.3.0. Geological Survey of Norway, Trondheim, N-7441.

[2] Chang, W.P., Nabyvanets, Y.B. and Jen, M.H. (2001) Unusual ${ }^{232}$ Th and ${ }^{238}$ U Contamination on Some Road Surfaces in Taoyuan, Taiwan. Health Physics, 80, 602-604. http://dx.doi.org/10.1097/00004032-200106000-00012

[3] Chen, Y.-F., Lin, J.-W., Sheu, R.-J., Lin, U.-T. and Jiang, S.-H. (2011) Measurement of Natural Background Radiation Intensity on a Train. Radiation Protection Dosimetry, 144, 663-667. http://dx.doi.org/10.1093/rpd/ncq308

[4] Sumithrarachchi, C.S. and Hewamanna, R. (2001) Terrestrial Gamma Dose Rates along One of the Coastal Highways in Sri Lanka. Sri Lankan Journal of Physics, 2, 1-6.

[5] Turhan, S., Arıkan, I.H., Oguz, F., Ozdemir, T., Yucel, B., Varinlioglu, A. and Kose, A. (2012) Car-Borne Survey of Natural Background Gamma Dose Rate in Çanakkale Region, Turkey. Radiation Protection Dosimetry, 148, 45-50. http://dx.doi.org/10.1093/rpd/ncq593

[6] Bou-Rabee, F. (1997) Soil Radioactivity Atlas of Kuwait. Environmental International, 23, 5-15. http://dx.doi.org/10.1016/S0160-4120(96)00073-6

[7] Bou-Rabee, F. (1995) Contribution of Uranium to Gross Alpha Radioactivity in Some Environmental Samples in Kuwait. Environmental International, 21, 293-298. http://dx.doi.org/10.1016/0160-4120(95)00022-D

[8] Al-Azmi, D. (2013) Performance of Some Radiation Dosimeters Used for Ambient Dose Rate Measurements. International Journal of Low Radiation, 9, 95-109. http://dx.doi.org/10.1504/IJLR.2013.055597

[9] Al-Azmi, D., Karunakara, N. and Mustapha, A. (2013) Teaching about Background Radiation. Physics Education, 48, 506-511. http://dx.doi.org/10.1088/0031-9120/48/4/506

[10] UNSCEAR (2000) Exposures from Natural Radiation Sources. ANNEX B.

[11] KISR (2008) Radiological Atlas for the State of Kuwait. Kuwait Institute for Scientific Research, Kuwait. 
Scientific Research Publishing (SCIRP) is one of the largest Open Access journal publishers. It is currently publishing more than 200 open access, online, peer-reviewed journals covering a wide range of academic disciplines. SCIRP serves the worldwide academic communities and contributes to the progress and application of science with its publication.

Other selected journals from SCIRP are listed as below. Submit your manuscript to us via either submit@scirp.org or Online Submission Portal.
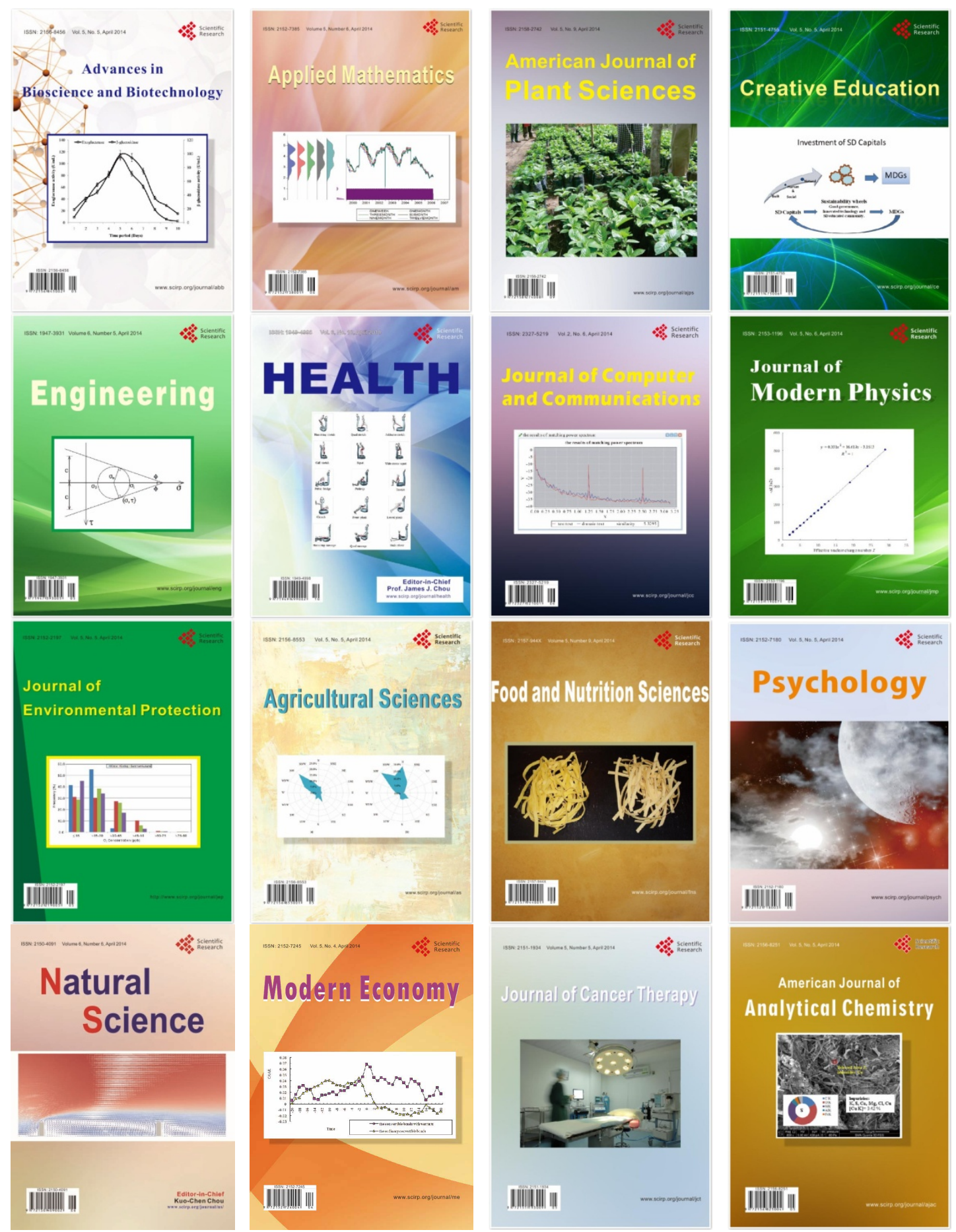